\title{
The role of work-related and personal factors in diabetes self-management
}

\author{
Iris Weijman ${ }^{\mathrm{a}}$, Wynand J.G. Ros ${ }^{\mathrm{a}, *}$, Guy E.H.M. Rutten ${ }^{\mathrm{a}}$, Wilmar B. Schaufeli ${ }^{\mathrm{b}}$, \\ Marc J. Schabracq ${ }^{\mathrm{c}}$, Jacques A.M. Winnubst ${ }^{\mathrm{a}}$ \\ ${ }^{a}$ University Medical Center Utrecht, Julius Center for Health Sciences and Primary Care, \\ Section of Medical and Health Psychology (Str. 3.130), P.O. Box 85060, 3508 AB Utrecht, The Netherlands \\ ${ }^{\mathrm{b}}$ Utrecht University, Department of Social and Organizational Psychology, Utrecht, The Netherlands \\ ${ }^{\mathrm{c}}$ University of Amsterdam, Department of Work and Organizational Psychology, Amsterdam, The Netherlands
}

Received 10 December 2003; received in revised form 4 October 2004; accepted 14 October 2004

\begin{abstract}
The aim of this study was to investigate how factors in the workplace and personal factors are related to the frequency with which people with diabetes perform self-management activities and the degree to which they do or do not experience the performing of self-management activities as a burden. Two hundred and ninety-two employees with insulin-treated diabetes completed questionnaires on socio-demographic and illness-related background variables, work experience, diabetes self-efficacy, social support outside of work, coping styles and selfmanagement activities. The results indicate that employees who reported a high workload were more likely to perceive injecting insulin as a burden. The level of social support was positively related to the frequency of dietary self-management in type 2 diabetes and negatively related to the sense of being burdened by dietary self-management in type 1 diabetes. With respect to personal factors, we found that a diabetes avoidance coping style was associated particularly with infrequent blood glucose monitoring and a high sense of being burdened by blood glucose monitoring. Individuals with a low level of self-efficacy were more likely to perceive all types of self-management activities as a burden. These results may guide health professionals when counseling individuals with diabetes.
\end{abstract}

(C) 2004 Elsevier Ireland Ltd. All rights reserved.

Keywords: Employment; Personal factors; Self-management; Diabetes mellitus

\section{Introduction}

Diabetes is, to a great extent, a self-managed disease, which means that patients need to perform various activities by themselves. These activities include self-monitoring of blood glucose, proper use of medication, an appropriate eating plan, balancing and adjusting insulin medication, food and exercise (based on the circumstances and blood glucose levels) and engaging in regular exercise [1,2]. Daily self-management may be perceived as a burden, because of the effort required to perform these various activities [3] in addition to the need for flexibility [4]. Moreover, it may also

\footnotetext{
* Corresponding author. Tel.: +31 30 2538426; fax: +31 302539038 .

E-mail addresses: i.weijman@med.uu.nl (I. Weijman), w.j.g.ros@med.uu.nl (Wynand J.G. Ros).
}

be a frustrating task [5] because the results of selfmanagement are not always immediately obvious [6]. It is much easier to fulfill and continue behaviors that offer results in the short-term. When positive effects are only experienced in the long-term, the motivation to perform selfmanagement activities as frequently as necessary may be diminished. The counseling of employees with diabetes by health-care professionals thus requires awareness of all those factors which make self-management easier. Psychosocial factors that have been described as determinants of self-management are: self-efficacy [7,8], social support [8-10], and coping styles [11,12]. Nevertheless, it continues to be difficult to determine how these factors influence selfmanagement. Most studies that reported on factors related to self-management focused on (inter)personal factors, to the exclusion of other factors. In this context, Glasgow and 
Eakin highlight the role of the family and other important mediators such as the health-care system, the workplace environment, the working organization, and sociological and cultural factors of the community as a whole [1].

Because most self-management tasks have to be performed several times a day, self-management is also an important issue in the workplace. It can only be performed successfully if it is smoothly integrated into the working life. There is a scarcity of studies that focus on selfmanagement in the working diabetic population and on the barriers to self-management in the workplace [13]. But about one-third of the human resource staff queried, indicated that there are jobs in their company that make it difficult to carry out self-management [14]. On the basis of interviews with endocrinologists, it was concluded that 'objective' work conditions related to work schedule (e.g. shift work, overtime, irregular hours, and timing of meals) could most certainly be regarded as barriers to selfmanagement. Physical facilities, flexibility, degree of control by the worker, a set routine, and a consistent activity level seemed to make self-management at work easier [15]. In another study in which $19 \%$ of the participants neglected their self-management, one of the most common reasons for doing so was the irregular working hours [16]. Other factors in the workplace that were supposed to have an influence on self-management are work pressure, lack of control, attitudes and behavior of superiors and the individual sensitivity of co-workers [14]. There is no quantitative data on the relationship between work experience and self-management. This study examines the relationship between work-related factors, as described by the job demand-control-support (JDCS) model [17-19], and self-management. The main components of this model are job demands, decision latitude, and support, both from colleagues and superiors.

In this paper, we will report on how background variables (age, gender, educational level, marital status, working hours per week, number of colleagues in the department, and severity of disease) and work characteristics as defined by the JDCS model [17] are related to both the frequency of performing self-management activities and the degree to which self-management is perceived as a burden. First, it is hypothesized that less favorable working situations according to the JDCS model (i.e., high demands, low control, or low support) are related to infrequent self-management and a high perception of self-management as a burden. This is in line with the results of Peyrot et al. who concluded that people with diabetes have difficulty maintaining their self-management activities when they are stressed [11]. Therefore, we assume that job stress, as induced by high demands, low control, or low support impedes self-management activities. Because the literature suggested that personal and social factors have an influence on diabetes self-management, we explored the additional role of coping, self-efficacy, and social support.

\section{Methods}

\subsection{Study population}

The participants were employees with insulin-treated diabetes mellitus (types 1 and 2) aged between 30 and 60 years who were selected from three outpatient diabetes clinics (academic hospital, regional hospital, center specializing in diabetes consultation) in the Netherlands. Employees in this age category have a relatively stable working position. Internal physicians selected patients with types 1 and 2 diabetes requiring insulin medication (diagnosis based on their own judgment). They did not select any patients from whom they knew that they were not employed. In one clinic, all patients were invited to take part, and one of the researchers (IW) selected, at random, a group of patients from each of the other two clinics. It was our intention to invite an equal number of people with types 1 and 2 diabetes. They received a letter from their physician inviting them to participate in our study. They also received information about the study and a form to confirm their participation. Of the 626 patients who were approached to participate in our study and who met the inclusion criteria, 347 were willing, and filled in the informed consent form (response rate $55.4 \%$ ). In total, 317 persons (166 with type 1 and 151 with type 2 diabetes) filled-in and returned the set of questionnaires. A reminder was sent after 4 weeks. Data on 25 subjects were rejected because they did not meet the inclusion criteria or they did not fill in the questionnaire properly. Consequently, our results are based on data from 292 participants.

\subsection{Measures}

Seven questions concerned background variables of age, gender, educational level, having a partner, hours per week worked, number of colleagues in the department, and selfreported long-term complications of diabetes. On the basis of self-reported long-term complications of diabetes, we established an index of disease severity: 0 'no complications', 1 'micro- or macro-vascular complications' and 2 'micro- as well as macro-vascular complications'. This index was also used in a study on quality-of-life in Dutch diabetes patients [20].

Job characteristics were assessed by using five scales of the questionnaire on the experience and assessment of work (Dutch abbreviation: VBBA) [21,22]. Based on the JDCS model [17-19], psychological demands of work were measured using the 'work pace and amount of work' scale (11 items, e.g. 'Do you have to work under time pressure?'), decision latitude using the 'job autonomy' scale (11 items, e.g. 'Are you allowed to decide the order in which you perform your tasks?') and the 'participation in decisionmaking' scale ( 8 items, e.g. 'Do you have any influence on what is and what isn't part of your task?'), social support using the 'support from colleagues' scale ( 9 items, e.g. 'Do 
you have a good relationship with your colleagues?') and the 'support from the direct superior' scale (9 items, e.g. 'Can you rely on your supervisor when you experience problems in your work?'). The job autonomy and participation in work scales (measure of decision latitude) were combined to establish one score as well as the support from colleagues and support from superior scales (measure of social support) $[17,18]$. A 4-point response scale was used, ranging from 0 'never' to 3 'always'. In accordance with the test manual [21], scores for each VBBA subscale were converted into 0100 scores. High scores indicate a lot of problems regarding the specific dimension. Cronbach's Alphas for the job demands, decision latitude, and support scales were, respectively, 0.88, 0.94, and 0.89 .

Coping was measured using a diabetes-specific coping measure, the diabetes coping measure (DCM) [23] and a general coping scale, the coping inventory for stressful situations (CISS) [24]. The DCM consists of four scales: tackling spirit coping (5 items), avoidance coping (5 items), passive resignation coping ( 5 items), diabetes integration coping (6 items) (5-point Likert scaling, ranging from 1 'disagree' to 5 'agree strongly'). Mean subscale scores were converted into 0-100 scores. High scores on the diabetes integration and tackling coping spirit indicate more adaptive coping. High scores on the avoidance and passive resignation scales indicate poor coping. The CISS assesses three coping dimensions: task-oriented ( 7 items), emotionoriented (7 items), and avoidance-oriented ( 7 items). Items can be rated on a 5-point frequency scale, ranging from 1 'not at all' to 5 'very much'. Scores for all scales range from 7 to 35 .

Social support from the social environment (family, friends) was assessed using a scale based on the co-worker and supervisor support scales of the VBBA. Scores range from 0 to 100, with high scores indicating a lack of support. Coefficient $\alpha$ for this scale is 0.87 .

The diabetes management self-efficacy scale for patients with diabetes was used to measure the level of self-efficacy in relation to diabetes self-management: nutritional selfmanagement, weight control, medical treatment, physical exercise, and blood sugar control [7]. We adapted this 20item scale for individuals with insulin-treated diabetes mellitus, by replacing items related to taking tablets by items related to insulin injections (coefficient $\alpha$ : 0.91). Selfefficacy was measured with the phrase 'I think I'm able to ...', scored on a 5-points scale: 1 'yes, surely'; 2 'probably yes'; 3 'maybe yes/maybe no'; 4 'probably not'; 5 'no, surely not'. High scores indicate low feelings of selfefficacy.

The multidimensional diabetes self-management checklist (MDSC) was developed by the authors to measure the frequency of performing self-management and perceived burden of doing so [25]. Four domains of self-management for individuals with insulin-treated diabetes were differentiated, which may be difficult to plan for, and interfere with one's daily routines: dietary self-management (follow- ing dietary guidelines, eating regularly), injecting insulin (frequency and dose), blood glucose monitoring, and adjusting the insulin dosage to specific circumstances. For each activity, the frequency of self-management was assessed by means of one item, formulated as: 'How often do you ... (e.g., monitor your blood glucose level yourself)?', with six response categories ranging from 1 'less often than once a month' to 6 'every day'. The checklist also included items on the perceived burden of selfmanagement. Items were formulated about the perceived burden in three life domains: home, work, and special occasions. For each activity, the burden was assessed by means of the phase 'Is it difficult for you to ...', for each life domain separately. Each item had four response categories: 0 'no, I (almost) never perceive it as a burden'; 1 'sometimes'; 2 'often'; 3 'yes, it is most of the time'. For each type of self-management, a burden sum score was established on the basis of the corresponding items, which range from 0 to 100 . Regarding the burden of dietary selfmanagement, a sum score was calculated based on the items about following dietary guidelines as well as about eating regularly, with a coefficient $\alpha$ of 0.75 . For the other burden scales coefficient $\alpha$ was 0.77 (insulin injection), 0.79 (blood glucose monitoring), and 0.90 (adjusting insulin).

\subsection{Data analysis}

SPSS 10.0.5 was used to analyze the data. For the analyses, variables on the original MDSC were dichotomized into high (every day) or low frequent (less often than every day) self-management and high or low perceived burden of performing self-management.

\subsubsection{Step $1-t$-tests}

In order to reduce the number of variables for logistic regression analyses, we first conducted $t$-tests. In the $t$-tests, we determined differences in means for background variables, work characteristics, and personal factors for participants who frequently or less frequently perform selfmanagement activities and those who perceive this as a burden or not. These analyses were conducted for each type of self-management activity and for persons with type 1 (DM1) and type 2 diabetes (DM2) separately. Those variables that were selected had two or more $t$-values with a $P$-value $<0.10$, for frequency and/or burden of selfmanagement. Because the sample sizes per group regarding the frequency of insulin injections were too small, analyses were not performed for this variable. Correlation coefficients between all independent variables were calculated to check for colinearity.

\subsubsection{Step 2 - logistic regression analyses}

Multivariate logistic regression analyses were performed in three steps to examine the association between background variables, work characteristics, personal factors, and self-management. All the selected background variables 
(step 1) were first entered into the model. Next, all the work factors were entered. Finally, personal factors (coping, social support, and self-efficacy) were entered stepwise into the model to find out whether these variables were related to self-management while controlling for the other variables. In order to improve the interpretation of the odds ratios in relation to each other, continuous variables were divided by their own standard deviation [26]. Analyses have been conducted for persons with DM1 and DM2 separately because the effects of behavioral and psychosocial factors may be different for different disease states [11].

Table 1

Study population $(N=292)$; description of: (a) background variables and personal factors, and (b) work-related factors

\begin{tabular}{|c|c|c|c|}
\hline & Total (292) & DM1 (159) & DM2 (133) \\
\hline \multicolumn{4}{|l|}{ (a) Background variables and personal factors } \\
\hline Age (years) & $44.55(8.78)$ & $40.32(7.60)$ & $49.72(7.17)$ \\
\hline Gender ( $\%$ male $)$ & $66.8 \%$ & $59.7 \%$ & $75.2 \%$ \\
\hline \multicolumn{4}{|l|}{ Educational level } \\
\hline Lower & $35.2 \%$ & $26.9 \%$ & $45.6 \%$ \\
\hline Middle & $32.0 \%$ & $32.7 \%$ & $31.2 \%$ \\
\hline Higher & $32.7 \%$ & $40.4 \%$ & $23.2 \%$ \\
\hline Having a partner (yes) & $86.0 \%$ & $84.8 \%$ & $87.5 \%$ \\
\hline \multicolumn{4}{|l|}{ Seriousness of disease } \\
\hline No complications & $56.2 \%$ & $56.6 \%$ & $55.6 \%$ \\
\hline Micro- or macrovascular complications & $37.7 \%$ & $38.4 \%$ & $36.8 \%$ \\
\hline Micro- and macrovascular complications & $6.2 \%$ & $5.0 \%$ & $7.5 \%$ \\
\hline $\mathrm{HbA} 1 \mathrm{c} \%$ & $8.20(1.21)$ & $8.12(1.12)$ & $8.30(1.31)$ \\
\hline Diabetes tackling spirit coping $(0-100)$ & $66.61(14.64)$ & $66.34(14.09)$ & $66.94(15.32)$ \\
\hline Diabetes avoidance coping $(0-100)$ & $26.26(22.15)$ & $25.90(21.64)$ & $26.70(22.82)$ \\
\hline Diabetes passive resignation coping $(0-100)$ & $25.20(21.15)$ & $23.67(20.04)$ & $27.03(22.35)$ \\
\hline Diabetes integration coping $(0-100)$ & $65.23(20.92)$ & $66.51(20.97)$ & $63.70(20.84)$ \\
\hline Avoidance coping (7-35) & $17.81(4.67)$ & $17.81(4.80)$ & $17.82(4.52)$ \\
\hline Task-oriented coping (7-35) & $20.74(3.94)$ & $21.08(3.82)$ & $20.34(4.07)$ \\
\hline Emotion-oriented coping (7-35) & $19.59(4.44)$ & $20.03(4.26)$ & $19.06(4.61)$ \\
\hline Lack of support from family and friends $(0-100)$ & $29.26(18.53)$ & $21.11(12.51)$ & $29.76(19.49)$ \\
\hline Lack of self-efficacy $(20-100)$ & $33.57(10.24)$ & $31.63(9.29)$ & $35.84(10.86)$ \\
\hline$\%$ Frequent following dietary guidelines & $70.8 \%$ & $73.0 \%$ & $68.2 \%$ \\
\hline$\%$ Frequent regular eating patterns & $65.6 \%$ & $63.5 \%$ & $68.2 \%$ \\
\hline$\%$ Frequent injecting of insulin & $96.1 \%$ & $93.3 \%$ & $99.2 \%$ \\
\hline$\%$ Frequent blood glucose monitoring & $47.8 \%$ & $57.6 \%$ & $35.9 \%$ \\
\hline$\%$ Adjusting insulin & $54.3 \%$ & $67.1 \%$ & $38.9 \%$ \\
\hline$\%$ Burden of dietary self-management & $70.4 \%$ & $66.0 \%$ & $75.8 \%$ \\
\hline$\%$ Burden of injecting insulin & $12.8 \%$ & $11.3 \%$ & $14.5 \%$ \\
\hline$\%$ Burden of blood glucose monitoring & $54.0 \%$ & $54.7 \%$ & $53.0 \%$ \\
\hline$\%$ Burden of adjusting insulin & $32.8 \%$ & $28.3 \%$ & $38.3 \%$ \\
\hline \multicolumn{4}{|l|}{ (b) Work-related factors } \\
\hline \multicolumn{4}{|l|}{ Occupational groups } \\
\hline Public services (education, culture, healthcare, and government) & $23.2 \%$ & $26.6 \%$ & $19.6 \%$ \\
\hline Agrarian, industry, and transportation & $27.0 \%$ & $24.3 \%$ & $32.3 \%$ \\
\hline Services (business, sales workers, and general administrative) & $43.9 \%$ & $46.8 \%$ & $40.6 \%$ \\
\hline Other & $5.9 \%$ & $2.6 \%$ & $7.5 \%$ \\
\hline \multicolumn{4}{|l|}{ Number of colleagues in the department } \\
\hline $1-5$ & $35.2 \%$ & $28.4 \%$ & $43.4 \%$ \\
\hline $6-20$ & $32.4 \%$ & $36.1 \%$ & $27.9 \%$ \\
\hline $21-100$ & $26.8 \%$ & $31.0 \%$ & $21.7 \%$ \\
\hline $100-1000$ & $5.3 \%$ & $4.5 \%$ & $6.2 \%$ \\
\hline$>1000$ & $0.4 \%$ & $0.0 \%$ & $0.8 \%$ \\
\hline \multicolumn{4}{|l|}{$\%$ Colleagues that know about their diabetes } \\
\hline All colleagues know & $75.0 \%$ & $76.1 \%$ & $73.6 \%$ \\
\hline Some colleagues know & $21.9 \%$ & $22.0 \%$ & $21.7 \%$ \\
\hline None of the colleagues know & $3.1 \%$ & $1.9 \%$ & $4.7 \%$ \\
\hline$\%$ Superiors that know about their diabetes & $92.3 \%$ & $93.3 \%$ & $91.0 \%$ \\
\hline Working hours per week & $36.38(14.63)$ & $34.90(12.51)$ & $38.15(16.70)$ \\
\hline Workload $(0-100)$ & $45.23(16.59)$ & $44.23(16.41)$ & $46.44(16.79)$ \\
\hline Lack of decision latitude $(0-100)$ & $37.45(21.13)$ & $38.27(17.57)$ & $36.44(24.87)$ \\
\hline Lack of support at work $(0-100)$ & $21.86(13.74)$ & $21.11(12.51)$ & $22.84(15.21)$ \\
\hline
\end{tabular}

Data in percentages and means (S.D.). 


\section{Results}

Characteristics of the study sample are shown in Table 1. Of the total population, which comprised 292 subjects, $54.5 \%$ had type 1 diabetes (mean age 40.32; S.D. $=7.60$ ) and $45.5 \%$ had type 2 diabetes (mean age 49.72; S.D. $=7.17$ )

On the basis of $t$-tests (step 1), it was concluded that, in respect to background variables, the participants' educational level, age, working hours per week, and seriousness of disease were relevant in relation to self-management, while gender, having a partner, and the number of employees in the department were not. All work-related factors were relevant to self-management. In regard to personal factors, diabetes coping styles - except diabetes tackling spirit coping - were related to self-management as well as self-efficacy and support from family and friends. General coping styles were not relevant to either frequency of self-management or perceived burden of self-management, nor were they selected for further regression analyses.

The selected variables were low to moderately interrelated. Correlation coefficients range from 0.00 to 0.49 . Three coefficients were higher than 0.40 , namely with regard to relations between support at work and support from family and friends ( $r=0.44)$, between decision latitude

Table 2

The relationship between background variables, work factors, personal factors, and frequency of performed self-management activities

\begin{tabular}{|c|c|c|c|c|}
\hline & \multicolumn{2}{|l|}{ DM1 } & \multicolumn{2}{|l|}{ DM2 } \\
\hline & $B$ & Odds ratio $(95 \% \mathrm{CI})$ & $B$ & Odds ratio $(95 \% \mathrm{CI})$ \\
\hline \multicolumn{5}{|l|}{ Following dietary guidelines } \\
\hline Educational level & 0.18 & $1.20(0.73-1.98)$ & -0.33 & $0.72(0.41-1.27)$ \\
\hline Age (per S.D. increase) & $0.70^{* *}$ & $2.01(1.18-3.43)$ & 0.46 & $1.58(0.89-2.81)$ \\
\hline Working hours per week (per S.D. increase) & 0.27 & $1.31(0.77-2.22)$ & 0.58 & $1.78(0.75-2.08)$ \\
\hline Seriousness of disease & 0.08 & $1.09(0.54-2.19)$ & -0.33 & $0.73(0.34-1.56)$ \\
\hline Workload (per S.D. increase) & -0.12 & $0.89(0.58-1.37)$ & 0.35 & $1.42(0.86-2.33)$ \\
\hline Lack of decision latitude (per S.D. increase) & 0.13 & $1.14(0.65-1.99)$ & -0.07 & $0.93(0.58-1.49)$ \\
\hline Lack of support at work (per S.D. increase) & -0.02 & $0.98(0.59-1.65)$ & $-0.54^{*}$ & $0.58(0.36-0.93)$ \\
\hline Diabetes avoidance coping & $-\mathbf{0 . 4 5}$ & $0.64(0.43-0.96)$ & - & - \\
\hline \multicolumn{5}{|l|}{ Eating regularly } \\
\hline Educational level & $-0.52^{*}$ & $0.60(0.36-1.00)$ & $-0.69^{*}$ & $0.50(0.28-0.89)$ \\
\hline Age (per S.D. increase) & $0.51^{*}$ & $1.67(1.02-2.72)$ & 0.26 & $1.30(0.73-2.32)$ \\
\hline Working hours per week (per S.D. increase) & -0.09 & $0.91(0.54-1.53)$ & -0.12 & $0.88(0.60-1.31)$ \\
\hline Seriousness of disease & 0.14 & $1.15(0.58-2.31)$ & -0.55 & $0.58(0.26-1.26)$ \\
\hline Workload (per S.D. increase) & -0.19 & $0.83(0.53-1.27)$ & -0.14 & $0.87(0.54-1.41)$ \\
\hline Lack of decision latitude (per S.D. increase) & -0.16 & $0.85(0.48-1.51)$ & 0.04 & $1.04(0.65-1.66)$ \\
\hline Lack of support at work (per S.D. increase) & -0.15 & $0.86(0.52-1.42)$ & -0.08 & $0.92(0.57-1.49)$ \\
\hline Lack of support family/friends (per S.D. increase) & - & - & $-0.49^{*}$ & $0.61(0.38-0.99)$ \\
\hline Lack of self-efficacy (per S.D. increase) & $-\mathbf{0 . 5 8} 8^{* *}$ & $0.56(0.36-0.87)$ & - & - \\
\hline \multicolumn{5}{|l|}{ Blood glucose monitoring } \\
\hline Educational level & $0.72^{* *}$ & $2.06(1.24-3.40)$ & 0.20 & $1.23(0.70-2.14)$ \\
\hline Age (per S.D. increase) & -0.35 & $0.70(0.44-1.13)$ & -0.27 & $0.77(0.45-1.32)$ \\
\hline Working hours per week (per S.D. increase) & 0.06 & $1.06(0.64-1.75)$ & 0.20 & $1.22(0.82-1.82)$ \\
\hline Seriousness of disease & 0.36 & $1.43(0.71-2.89)$ & 0.41 & $1.51(0.72-3.17)$ \\
\hline Workload (per S.D. increase) & 0.15 & $1.16(0.77-1.75)$ & 0.17 & $1.19(0.74-1.91)$ \\
\hline Lack of decision latitude (per S.D. increase) & 0.22 & $1.25(0.73-2.13)$ & 0.29 & $1.33(0.85-2.09)$ \\
\hline Lack of support at work (per S.D. increase) & 0.14 & $1.15(0.72-1.86)$ & -0.09 & $0.91(0.59-1.42)$ \\
\hline Diabetes avoidance coping (per S.D. increase) & $-0.94^{* * *}$ & $0.39(0.24-0.63)$ & $-\mathbf{0 . 7 0} * *$ & $0.50(0.30-0.82)$ \\
\hline Diabetes integration coping (per S.D. increase) & $-\mathbf{0 . 4 8}$ & $0.62(0.40-0.97)$ & - & - \\
\hline \multicolumn{5}{|l|}{ Adjusting insulin } \\
\hline Educational level & 0.28 & $1.32(0.82-2.14)$ & $0.74^{*}$ & $2.10(1.19-3.72)$ \\
\hline Age (per S.D. increase) & -0.15 & $0.86(0.54-1.38)$ & -0.31 & $0.74(0.41-1.32)$ \\
\hline Working hours per week (per S.D. increase) & 0.41 & $1.51(0.91-2.52)$ & -0.03 & $0.98(0.63-1.51)$ \\
\hline Seriousness of disease & 0.36 & $1.44(0.71-2.90)$ & -0.58 & $0.56(0.24-1.30)$ \\
\hline Workload (per S.D. increase) & 0.14 & $1.15(0.76-1.74)$ & $0.73^{* *}$ & $2.08(1.24-3.47)$ \\
\hline Lack of decision latitude (per S.D. increase) & 0.14 & $1.15(0.67-1.97)$ & -0.20 & $0.82(0.51-1.32)$ \\
\hline Lack of support at work (per S.D. increase) & 0.05 & $1.05(0.65-1.69)$ & -0.38 & $0.69(0.42-1.13)$ \\
\hline Diabetes avoidance coping (per S.D. increase) & $-0.55^{* *}$ & $0.59(0.38-0.87)$ & - & - \\
\hline Diabetes integration coping & $-0.53^{*}$ & $0.59(0.38-0.92)$ & - & - \\
\hline
\end{tabular}

$B$-values with significance levels and odds ratios (with 95\% confidence interval), final model. Types 1 and 2 diabetes separately.

* $P<0.05$.

** $P<0.01$.

*** $P<0.001$ 
and support at work $(r=0.42)$, and between integration coping and passive resignation coping $(r=-0.49)$. Based on the results, colinearity is not likely to play a role.

\subsection{Relationships with frequency of performing self- management activities (Table 2)}

\subsubsection{Background variables}

Multivariate analyses showed that there were few relationships between background variables (educational level, age, seriousness of disease, and working hours per week) and frequency of self-management (see Table 2). A higher level of education was associated with more frequent blood glucose monitoring in DM1 and more adjusting of insulin dosages in DM2. Conversely, employees with DM1 and DM2 with a higher educational level were less likely to report frequent regular eating patterns. Being older was related positively to the frequency of following recommended nutritional guidelines and regular eating in DM1.

\subsubsection{Work-related factors}

The results indicated that few work-related variables had relationships with self-management behavior. For persons with DM2, little support at work corresponded to the less diligent following of an appropriate eating plan. A higher workload corresponded to more frequent adjustments of insulin dosages to existing circumstances in DM2. For persons with DM1, no relations were found between

Table 3

The relationship between background variables, work factors, personal factors, and perceived burden of self-management activities

\begin{tabular}{|c|c|c|c|c|}
\hline & \multicolumn{2}{|l|}{ DM1 } & \multicolumn{2}{|l|}{ DM2 } \\
\hline & $B$ & Odds ratio $(95 \% \mathrm{CI})$ & $B$ & Odds ratio $(95 \% \mathrm{CI})$ \\
\hline \multicolumn{5}{|l|}{ Burden of dietary self-management } \\
\hline Educational level & 0.27 & $1.31(0.80-2.13)$ & -0.52 & $0.59(0.30-1.17)$ \\
\hline Age (per S.D. increase) & -0.23 & $0.79(0.50-1.26)$ & -0.57 & $0.56(0.24-1.32)$ \\
\hline Working hours per week (per S.D. increase) & 0.33 & $1.39(0.83-2.32)$ & 0.03 & $1.03(0.55-1.91)$ \\
\hline Seriousness of disease & -0.07 & $0.93(0.46-1.87)$ & -0.05 & $0.95(0.35-2.58)$ \\
\hline Workload (per S.D. increase) & 0.00 & $1.00(0.66-1.51)$ & -0.14 & $0.87(0.49-1.55)$ \\
\hline Lack of decision latitude (per S.D. increase) & -0.02 & $0.98(0.56-1.71)$ & -0.21 & $0.81(0.45-1.48)$ \\
\hline Lack of support at work (per S.D. increase) & $0.54^{*}$ & $1.71(1.04-2.80)$ & 0.21 & $1.23(0.67-2.24)$ \\
\hline Lack of self-efficacy (per S.D. increase) & $0.66 *$ & $1.94(1.15-3.26)$ & $1.67^{* * *}$ & $5.30(2.21-12.71)$ \\
\hline \multicolumn{5}{|l|}{ Burden of injecting insulin } \\
\hline Educational level & -0.23 & $0.79(0.31-2.00)$ & -0.28 & $0.76(0.34-1.70)$ \\
\hline Age (per S.D. increase) & -0.36 & $0.69(0.31-1.57)$ & 0.08 & $1.08(0.48-2.42)$ \\
\hline Working hours per week (per S.D. increase) & 1.11* & $3.02(1.10-8.31)$ & 0.07 & $1.08(0.69-1.67)$ \\
\hline Seriousness of disease & 0.49 & $1.63(0.57-4.61)$ & -0.48 & $0.62(0.20-1.88)$ \\
\hline Workload (per S.D. increase) & $\mathbf{0 . 8 3}^{*}$ & $2.29(1.01-5.17)$ & $0.77^{*}$ & $2.15(1.06-4.36)$ \\
\hline Lack of decision latitude (per S.D. increase) & -0.22 & $0.80(0.29-2.23)$ & 0.12 & $1.13(0.61-2.10)$ \\
\hline Lack of support at work (per S.D. increase) & 0.70 & $2.01(0.88-4.58)$ & -0.18 & $0.84(0.44-1.60)$ \\
\hline Lack of self-efficacy & $0.81^{*}$ & $2.24(1.11-4.50)$ & $0.91^{* *}$ & $2.48(1.27-4.84)$ \\
\hline Diabetes integration coping & - & - & $-0.82^{*}$ & $0.44(0.21-0.92)$ \\
\hline \multicolumn{5}{|l|}{ Burden of blood glucose monitoring } \\
\hline Educational level & 0.40 & $1.50(0.92-2.45)$ & 0.12 & $1.12(0.63-2.00)$ \\
\hline Age (per S.D. increase) & 0.14 & $1.15(0.72-1.83)$ & 0.12 & $1.13(0.65-1.97)$ \\
\hline Working hours per week (per S.D. increase) & 0.48 & $1.61(0.96-2.70)$ & 0.10 & $1.10(0.75-1.62)$ \\
\hline Seriousness of disease & 0.02 & $1.02(0.52-2.02)$ & 0.32 & $1.38(0.64-2.95)$ \\
\hline Workload (per S.D. increase) & 0.05 & $1.05(0.70-1.58)$ & 0.26 & $1.30(0.82-2.08)$ \\
\hline Lack of decision latitude (per S.D. increase) & 0.38 & $1.47(0.84-2.57)$ & 0.20 & $1.22(0.77-1.93)$ \\
\hline Lack of support at work (per S.D. increase) & -0.10 & $0.91(0.57-1.45)$ & -0.19 & $0.83(0.52-1.32)$ \\
\hline Diabetes avoidance coping & $0.63^{* *}$ & $1.88(1.22-2.90)$ & $1.06 * * *$ & $2.90(1.62-5.18)$ \\
\hline Lack of self-efficacy & $0.51^{*}$ & $1.66(1.04-2.66)$ & - & - \\
\hline \multicolumn{5}{|l|}{ Burden of adjusting insulin } \\
\hline Educational level & 0.39 & $1.48(0.83-2.63)$ & -0.06 & $0.94(0.55-1.63)$ \\
\hline Age (per S.D. increase) & 0.09 & $1.09(0.63-1.88)$ & -0.12 & $0.89(0.50-1.56)$ \\
\hline Working hours per week (per S.D. increase) & 0.13 & $1.13(0.65-1.99)$ & 0.01 & $1.01(0.69-1.48)$ \\
\hline Seriousness of disease & 0.07 & $1.08(0.49-2.35)$ & $0.76^{*}$ & $2.15(1.01-4.57)$ \\
\hline Workload (per S.D. increase) & -0.18 & $0.84(0.52-1.35)$ & 0.01 & $1.01(0.63-1.61)$ \\
\hline Lack of decision latitude (per S.D. increase) & 0.23 & $1.25(0.66-2.37)$ & 0.32 & $1.38(0.88-2.17)$ \\
\hline Lack of support at work (per S.D. increase) & 0.22 & $1.25(0.73-2.14)$ & -0.19 & $0.83(0.52-1.32)$ \\
\hline Lack of self-efficacy & $1.25^{* * *}$ & $3.48(2.05-5.89)$ & $0.64^{* *}$ & $1.89(1.17-3.05)$ \\
\hline
\end{tabular}

$B$-values with significance levels and odds ratios (with 95\% confidence interval), final model. Types 1 and 2 diabetes separately.

${ }^{*} P<0.05$.

*** $P<0.01$.

**** $P<0.001$. 
the way employees with diabetes perceived their workload, decision latitude and support at work and selfmanagement.

\subsubsection{Personal factors}

Several relationships were found between personal factors and frequency of self-management. Diabetes avoidance coping was related to the frequency with which people with DM1 follow recommended dietary guidelines and to the adjustment of their insulin dosages. Avoidance coping was also related to the frequency of blood glucose monitoring in both types of diabetes. In all cases, individuals with an avoidance coping style were less likely to perform self-management activities frequently. Few other relations were found between personal factors and the frequency of self-management. People with DM2 who considered that they received more support from family and friends and people with DM1 with a high sense of self-efficacy ate frequently and regularly. Furthermore, more diabetes integration coping was associated with less frequent blood glucose monitoring and adjusting insulin in DM1.

\subsection{Relationships with perceived burden of self-management (Table 3)}

\subsubsection{Background variables}

Few relationships were found between background variables and burden of self-management. Contrary to findings with regard to frequency of self-management, age, and educational were not related to the burden. Employees with DM1 with more working hours per week were more likely to perceive injecting insulin as a burden than people who work less hours per week. In the case of DM2, a more serious disease state was related to those who experienced it to be a burden to adjust insulin (see Table 3).

\subsubsection{Work-related factors}

Some relationships were found between work-related factors and the perceived burden of self-management. People with both types of diabetes who experience a high workload are more likely to perceive injecting insulin as a burden. People with DM1 who experience a lack of support at work perceive dietary self-management more as a burden.

\subsubsection{Personal factors}

Several relations were found between personal factors and the burden of self-management. It turned out that the level of self-efficacy especially had many relationships with the perceived burden of performing self-management activities. Strong feelings of being able to perform the different types of self-management activities related to a low perceived burden of performing these activities. Furthermore, people with DM2 with a diabetes integration coping style were less likely to perceive injecting insulin as a burden. People with DM1 with a low sense of self-efficacy were more likely to perceive blood glucose monitoring as a burden.

\section{Discussion and conclusion}

\subsection{Discussion}

Up to now, this is the first study describing relationships between work experience, personal factors, and selfmanagement in a diabetes working population. For this reason, we chose a cross-sectional design to explore which factors are likely to be important for performing selfmanagement tasks frequently and for performing tasks without perceiving it as burdensome. First, relationships were studied between background variables and selfmanagement. Age and the level of education were related to the frequency of self-management, while the number of working hours per week and seriousness of disease were related to the burden of self-management. The relationships between educational level and frequency of self-management were not consistent; employees with a higher level of education, plan their meals less rigidly, monitor their blood glucose more often, and also adjust their insulin more often. It can be speculated that employees with a higher education may be unable to eat regularly because they have less structured functions and have no fixed breaks. It is also possible that they have more flexible jobs and more control over their work and are therefore more flexible in their selfmanagement strategies. They probably have greater success in self-regulation during working hours, which is one of the challenges for employees with diabetes. Moreover, physicians probably give more structured advice, especially about their eating patterns to patients with less education.

Second, we investigated whether, and if so which, factors in the workplace were related to performing self-management activities in employees with diabetes as well as to the perceived burden thereof. Our results indicated that the frequency with which employees perform self-management activities and the level of workload, control, and support at work were relatively independent of each other. However, it appears that employees with both types 1 and 2 diabetes who have a higher workload are more likely to perceive injecting insulin as a burden than employees who have a lower workload. It is probable that workload was only related to the perceived burden of this type of self-management behavior because injecting insulin is necessary and unavoidable, even when there is time pressure. This is in agreement with the finding that $93 \%$ of people with DM1 and $99 \%$ of people with DM2 inject the recommended amount of insulin daily. In another European study [16], it was also found that $99 \%$ frequently injected insulin: $84 \%$ of the participants daily injected their insulin as scheduled and $15 \%$ almost daily. Based on the literature $[15,16]$, it was expected that control over one's work is important for the 
performance of self-management activities. However, in our study the lack of decision latitude was related neither to the frequency of self-management nor to the perceived burden of self-management. This may be due to the fact that most items on decision latitude are restricted to control over tasks and work-related activities (e.g. 'Can you decide how you perform your work?'). Probably, the fact that employees have less control over their work does not automatically imply that they cannot plan their self-management behavior. Furthermore, when people have no control over their work they may possibly perform self-management activities nonetheless, e.g. during the lunch or coffee break. Social support at work was only related to dietary self-management. More support was linked to more frequent selfmanagement in DM2 and to a lower perceived burden in DM1. This finding, contrary to other types of selfmanagement, can be explained by the fact that nutritional behavior is mostly embedded in a social context.

Additionally, we were interested in relations between a person's coping style, self-efficacy, and perceived social support and self-management. It turned out that personal factors were more relevant in relation to self-management than were factors on work experience. We will therefore discuss these results extensively. Many relations were found between self-efficacy and the burden of self-management. Contrary to theories on self-efficacy [27], our study showed that self-efficacy had a limited relationship to the frequency with which people perform self-management activities. Only, people with DM1 and a high level of self-efficacy were more likely to have regular eating patterns. However, we did find a number of links between avoidance coping and the frequency of self-management.

Employees with both types of diabetes and a diabetes avoidance coping style were less likely to monitor their blood glucose level frequently. They were also more likely to perceive blood glucose self-monitoring as a burden. Individuals with a diabetes avoidance coping style distract themselves with activities or thoughts that have nothing to do with diabetes to distract themselves from diabetes issues. Blood glucose monitoring gives direct feedback about the blood glucose level and this type of self-management activity may therefore be particularly confrontational for people with a diabetes avoidance coping style. Selfmanagement behaviors and the perceived burden thereof are unrelated to subjects' general coping styles. We were not surprised by this finding because diabetes self-management was measured using a disease-specific questionnaire while coping relates to all manners of situations, including those unrelated to diabetes. In the literature, including literature pertaining to other research areas, the same conclusions were drawn in respect to specificity of measurement instruments $[28,29]$. These findings underline the importance of disease-specific (coping) measures.

Furthermore, support from family and friends seemed only to be important for employees with DM2 in that they eat more frequently at regular times when they experience support. This is in line with the findings in respect to social support at work. Although they know themselves that they have to follow the nutritional guidelines, as we concluded earlier, support from family and friends possibly facilitates this because it is part of a social event. We did not find other relationships with social support, whereas other studies, such as a study by Toljamo and Hentinen [10], did find that support from family and friends was associated with adherence to self-care. However, results cannot be adequately compared because of differences in methodology. We did not made a distinction between different kinds of support - emotional, instrumental, informational - and appraisal [30] and certain types of social support may facilitate self-management while others may not. Therefore, in future research, more specific measures are preferable in order to detect the relationship between support and selfmanagement.

As for the limitations of the study, it should be noted that because of the explorative character of our study, we studied a variety of relationships. Although this implies that significant results need to be interpreted carefully because of the phenomenon of multiple testing, the most prominent results were consistent for the different measures of selfmanagement and diabetes types. For the results regarding the relationship between self-efficacy, diabetes avoidance coping, and self-management, the risk of unjustified significant results is minimal. Because self-report measures were used to assess the frequency with which employees perform self-management tasks, there is a risk that the results do not reflect their actual behavior. The percentage of people who daily inject their insulin may be overestimated, for example. Furthermore, cross-sectional data were used for the analyses, which implies that causal conclusions cannot be drawn. Although one can state that there are relationships to self-management, nothing can be said about the direction of effects. A further comment regards the assembly of the study population. Because we had a heterogeneous study population, there is no reason to assume that the results cannot be generalized to the general Dutch diabetes population. Patients of various ages who live in different regions of the Netherlands with different educational background and a variety of jobs participated. However, we cannot comment upon how representative our study is of the whole population.

\subsection{Conclusion}

From the findings of this study, it can be concluded that personal factors play a more prominent role in relationship to self-management than the way in which employees perceive their work situation. Employees in a work situation with a high workload, little decision latitude, and little support are no more likely to neglect their self-management compared to those in a more favorable situation. However, employees with an avoidance coping style do monitor their blood glucose level less frequently and also perceive this 
self-management task as a burden. Individuals who have a lower sense of self-efficacy feel more burdened by performing all self-management activities.

\subsection{Practice implications}

This explorative study gives rise to suggestions for further prospective research resulting in conclusions about various short-term and long-term relationships between work characteristics, personal factors, and self-management. Our results indicated that for some employees, it would be important to reduce the workload to make injecting insulin (at work) more feasible. Moreover, indications were found that increasing support at work helps to promote dietary self-management and makes it easier for employees to perform. It is recommended that it be ascertained whether factors in the workplace restrict self-management and make it more difficult. As Detaille et al. also concluded, occupational physicians should address and focus on selfmanagement issues [31]. As we indicated in the discussion, people who are more highly educated may have more flexibility in their work and may therefore better succeed in self-management. To regulate the blood glucose levels adequately, flexibility in self-management is seen as more important than it was in earlier decades [32]. Therefore, these aspects should be emphasized in self-management training programs. Lower educated employees can also be trained how to become more flexible in their disease management (at work).

Personal factors were found to be especially relevant in relation to self-management. Therefore, we think there is a prominent role for professionals (especially internal physicians, diabetes nurses, and psychologists) to identify problems with performing self-management activities. Results showed that a lack of self-efficacy and avoidance coping were particularly important factors in relation to selfmanagement. This was also concluded from Bandura's social learning theory and from the literature [27,33]. Enhancing people's sense of self-efficacy, by setting achievable targets, should be one of the essential elements and goals of self-management interventions. These interventions may include enhancing skill mastery, modeling, social persuasion, and the ability to re-interpret symptoms [34]. For the same reason that it is important to enhance selfefficacy, awareness of a diabetes avoidance coping style by professionals is of paramount importance in order to avoid infrequent self-management behavior and to prevent patients from perceiving the task of checking their blood glucose as a burden. Thus, during a consultation, the focus should not only be on self-management activities themselves, but also on the way patients think about their capacities to actually perform certain types of behavior and the way they cope with diabetes. To make self-management more manageable, it may be necessary to refer individuals to a psychologist for individual coaching or to a diabetes education program. If self-management in employees with diabetes is a problem, the focus should in the first place, be on identifying personal factors.

\section{Acknowledgments}

This work was supported by grants of Utrecht University and the Priority program 'Fatigue at work' of the Netherlands Organization for Scientific Research (NWO).

\section{References}

[1] Glasgow RE, Eakin EG. Issues in diabetes self-management. In: Shumaker SA, Schron EB, Ockene JK, McBee WL, editors. The Handbook of Health Behavior Change. New York: Springer; 1998. p. 435-61.

[2] Pennings-van der Eerden LJM, Visser AP. Diabetes mellitus. In: Kaptein AA, editor. Behavioral Medicine: Psychologische Behandeling van Lichamelijke Aandoeningen [Behavioural Medicine: Psychological Treatment of Somatic Disorders]. Chichester: Wiley; 1990. p. 247-64.

[3] Vermeire E, Wens J, van Royen P, Hearnshaw H. Interventions for improving adherence to treatment recommendations in people with type 2 diabetes mellitus. In: Protocol for a Cochrane Review. The Cochrane Library Issue 4. Oxford: Update Software; 2002.

[4] Watson M, Briganti E, Skinner T, Manning C. Self-management strategies for adults with type 1 diabetes mellitus. In: Protocol for a Cochrane Review. The Cochrane Library Issue 1. Oxford: Update Software; 2003.

[5] Polonsky WH. Understanding and assessing diabetes-specific quality of life. Diabetes Spectrum 2000;13:36-41.

[6] Jacobson AM, de Groot M, Samson J. Quality of life research in patients with diabetes mellitus. In: Dimsdale JE, Baum A, editors. Quality of Life in Behavioral Medicine Research. Hillsdale, NJ: Lawrence Erlbaum Associates; 1995. p. 241-62.

[7] van der Bijl J, van Poelgeest-Eeltink A, Shortridge-Baggett L. The psychometric properties of the diabetes management self-efficacy scale for patients with type-2 diabetes mellitus. J Adv Nurs 1999;30:352-9.

[8] Glasgow RE, Toobert DJ, Gillette CD. Psychosocial barriers to diabetes self-management and quality of life. Diabetes Spectrum 2001;14:33-41.

[9] Skinner TC, John M, Hampson SE. Social support and personal models of diabetes as predictors of self-care and well-being: a longitudinal study of adolescents with diabetes. J Pediatr Psychol 2000;25:257-67.

[10] Toljamo M, Hentinen M. Adherence to self-care and social support. J Clin Nurs 2001;10:618-27.

[11] Peyrot M, McMurry Jr JF, Kruger DF. A biopsychosocial model of glycemic control in diabetes: stress, coping and regimen adherence. J Health Soc Behav 1999;40:141-58.

[12] Nomura M, Fujimoto K, Higashino A, Denzumi M, Miyagawa M, Miyajima H, Nada T, Kondo Y, Tada Y, Kawaguchi R, Morishita T, Saito K, Ito S, Nakaya Y. Stress and coping behavior in patients with diabetes mellitus. Acta Diabetol 2000;37:61-4.

[13] Glasgow RE. Behavioral and psychosocial measures for diabetes care: what is important to assess? Diabetes Spectrum 1997;10:12-7.

[14] Padgett DL, Heins JM, Nord WR. Employers' perceptions of diabetes in the workplace. Diabetes Spectrum 1995;8:10-5.

[15] Heins JM, Arfken CL, Nord WR, Houston CA, McGill JB. The Americans with disabilities act and diabetes. Diabetes Care 1994;17:453. 
[16] Toljamo M, Hentinen M. Adherence to self-care and glycaemic control among people with insulin-dependent diabetes mellitus. J Adv Nurs 2001;34:780-6.

[17] Karasek R, Theorell T. Healthy Work: Stress, Productivity, and the Reconstruction of Working Life. New York: Basic Books; 1990.

[18] Karasek RA, Schwartz J, Theorell T. Job characteristics, occupation and coronary heart disease. Final Report to National Institute of Occupational Safety and Health. New York: Columbia University; 1982.

[19] Johnson JV, Hall EM. Job strain, workplace social support, and cardiovascular disease: a cross-sectional study of a random sample of the Swedish working population. Am J Public Health 1988;78: 1336-42.

[20] Redekop WK, Koopmanschap MA, Stolk RP, Rutten GEHM, Wolffenbuttel BHR, Niessen LW. Health-related quality of life and treatment satisfaction in Dutch patients with type 2 diabetes. Diabetes Care 2002;25:458-63.

[21] van Veldhoven M, Meijman TF, Broersen JPJ, Fortuin RJ. Handleiding VBBA: Onderzoek naar de beleving van psychosociale arbeidsbelasting en werkstress met behulp van de vragenlijst beleving en beoordeling van de arbeid [Manual Questionnaire on Psychological Job Demands and Job Stress]. Amsterdam: Stichting Kwaliteitsbevordering Bedrijfsgezondheidszorg; 1997.

[22] van Veldhoven M, de Jonge J, Broersen JPJ, Kompier MAJ, Meijman TF. Specific relationships between psychosocial job conditions and job-related stress: a three-level analytic approach. Work Stress 2002;16:207-28.

[23] Bradley C. Handbook of Psychology and Diabetes. Chur: Harwood Academic Publishers; 1994.

[24] Endler NS, Parker JDA. Assessment of multidimensional coping: task, emotion, and avoidance strategies. Psychol Assess 1994;6:50-60.

[25] Weijman I, Ros WJG, Rutten GEHM, Schaufeli WB, Schabracq MJ, Winnubst JAM. The multidimensional diabetes self-management checklist (MDSC) (internal report). Utrecht: University Medical Center Utrecht, Section of Medical and Health Psychology; 2003.

[26] Andrea H, Beurskens AJHM, Metsemakers JFM, van Amelsvoort LGPM, van den Brandt PA, van Schayck CP. Health problems and psychosocial work environment as predictors of long term sickness absence in employees who visited the occupational physician and/or general practitioner in relation to work: a prospective study. Occup Environ Med 2003;60:295-300.

[27] Bandura A. Social foundations of thought and action: a social cognitive theory. Englewood Cliffs: Prentice Hall; 1986.

[28] de Ridder DTD, Schreurs K. Coping, social support and chronic disease: a research agenda. Psychol Health Med 1996;1: $71-82$.

[29] Anderson RM, Fitzgerald JT, Wisdom K, Davis WK, Hiss RG. A comparison of global versus disease-specific quality-of-life measures in patients with NIDDM. Diabetes Care 1997;20:299-305.

[30] Langford CP, Bowsher J, Maloney JP, Lillis PP. Social support: a conceptual analysis. J Adv Nurs 1997;25:95-100.

[31] Detaille SI, Haafkens JA, van Dijk FJH. What employees with rheumatoid arthritis, diabetes mellitus and hearing loss need to cope at work. Scand J Work Environ Health 2003;29:134-42.

[32] Berger M, Mühlhauser I. Diabetes care and patient-oriented outcomes. J Am Med Assoc 1999;281:1676-8.

[33] Lorig KR, Sobel DS, Stewart AL, William Brown B, Bandura A, Ritter P, Gonzalez VM, Laurent DD, Holman HR. Evidence suggesting that a chronic disease self-management program can improve health status while reducing hospitalization: a randomized trial. Med Care 1999;37:5-14.

[34] The Robert Wood Johnson Foundation, The Center for the Advancement of Health. Essential elements of self-management interventions. Report of the Robert Wood Johnson Foundation and The Center for the Advancement of Health, 2002. http://www.rwjf. org/publications. 